\title{
Diastereo-selectivity in Diels-Alder Cycloadditions of Erythrose Benzylidene-acetal 1,3-Butadienes with Maleimides
}

\author{
Daniela A. L. Salgueiro; Vera C. M. Duarte; Cristina E.A. Sousa; Maria J. Alves ; António Gil \\ Fortes
}

Departamento de Química, Universidade do Minho, Campus de Gualtar, 4710-057 Braga, Portugal

\begin{abstract}
Maleimides were combined with D-erythrose benzylidene-acetal 1,3-butadienes 1 and $\mathbf{2}$ to study the facial selectivity of the Diels-Alder cycloadditions. The selectivity was found to be from moderate to good. The reaction diastereotopicity can be reversed with the temperature. Simultaneous coordination of diene 1, having a free hydroxyl group, and maleimide 3 to a chiral bimetallic Lewis acid catalyst (LACASA-DA reaction) occurs with complete diastereo-control to give a single adduct, using an extra chiral inductor either $R$ - or $S$ BINOL.
\end{abstract}

Small chiral synthons are being more and more appealing to synthetic chemists to build up target molecules possessing multi-stereogenic centres. We have been looking at the usefulness of D-erythrose 1,3-butadienes, like $\mathbf{1}$ and $\mathbf{2},{ }^{1}$ as chiral counterparts in diastereoselective Diels-Alder (DA) cycloadditions. In the past it was found a high diastereotopicity associated to Diels-Alder of these dienes to 2-methoxycarbonyl- $p$ benzoquinones. ${ }^{1}$ In a previous study in our laboratory a complete chiral induction was also found in $[4 \pi+2 \pi]$ cycloadditions of some D-erythrose benzylidene-acetal 1,3-butadienes, having an ether protection at C-5, with 4-phenyl-1,2,4-triazoline-3,5-dione (PTAD). ${ }^{2} \mathrm{NH}$-Maleimide (3) and $N$-phenylmaleimide (4) were now combined with D-erythrose dienes $\mathbf{1}$ and $\mathbf{2}$. The facial selectivity of the DA are moderate to good in thermal reactions, and interestingly the topicity was reversed when the cycloadditions were run at $5{ }^{\circ} \mathrm{C}$. Self-assembly of the components of the DA in a Lewis acid template turned the selectivity complete in two cases.

D-Erythrose benzylidene-acetal 1,3-butadienes possessing the alcohol function protected (like 2) reacted before with PTAD to give a single product, the endo, $S$ configuration adduct at the new stereogenic centre. ${ }^{2}$ The reaction turned out to be less selective when the diene bears an unprotected hydroxyl group at C-5, 1. Reacting now diene 2 with $N$-phenylmaleimide in dichloromethane (the solvent used in reactions with PTAD) the selectivity was reduced from complete to a 2:1 ratio of endo-diastereomers; the major being the $S$ isomer, $\mathbf{5}$, and the minor its 
diastereomer $R, 6$. The selectivity dropped to zero when diene 1 reacted with $N$ phenylmaleimide (4). The best selectivity with maleimides occurs when at least one of the reagents has the possibility of acting as a proton donor in a hydrogen bond: combination of diene 2 to $\mathrm{NH}$-maleimide $(\mathbf{3})$ affords a $3(S): 1(R)$ ratio of isomers; combination of diene 1 with $\mathrm{NH}$-maleimide (3) also yields the same ratio of isomers. Scheme 1 recorded the four possible combinations of the reagents. The reactions conditions and the yields of products are collected in table 1.

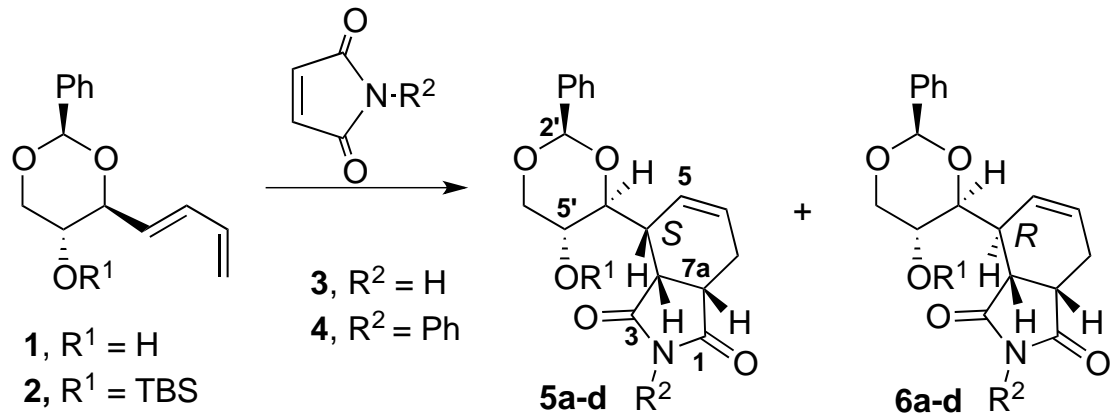

Scheme 1 - Four possible combinations of dienes $1 / 2$ to maleimides 3/4 giving compounds 5 and 6

Considering the unexpected behavior of maleimides in relation to PTAD, figure 1 shows a possible explanation for the fact. The reagents superimposition in pictures $\mathbf{A}, \mathbf{B}$ and $\mathbf{C}$ show the dienophiles approaches to the $r e$ face of the diene, leading to the $R$ configuration products. In case $\mathbf{A}$ the proximity in space between the two electronegative atoms of the diene and dienophile may result in repulsion between reagents and turn the approach unlikely. Picture $\mathbf{B}$ does not evidence repulsion due to the own nature of maleimides, which may result in a likely approach in case $\mathbf{B}$, that did not occur in case $\mathbf{A}$. Even so, as picture $\mathbf{C}$ shows, attack on the $s i$ face would result in a less bulky interaction between reagents, which may explain the $S$ configuration compounds as the major isomers in most reactions.

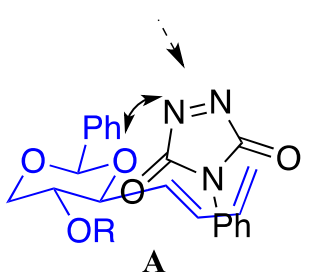

A

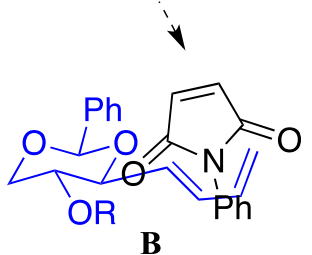

B

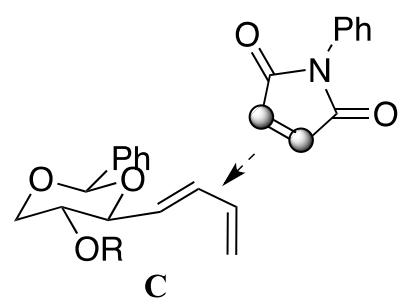

unfavored interaction less unfavored interaction favored interaction in reaction with PTAD in reaction with maleimide 4 with PTAD and maleimide 4

Figure 1- Different interaction at the rear double bond in maleimides and PTAD with the erythrose dienes $(\mathbf{A} / \mathbf{B}$ and $\mathbf{C})$ 
Table 1 displays some relevant reactions conditions employed in DA between erythrose dienes $(\mathbf{1 , 2})$ and maleimides $(\mathbf{3 , 4})$. In the majority of the cases a higher yield of the $S$-configuration product is observed. The reactions take usually some days, but in one case it was shortened from 5 days to $15 \mathrm{~h}$ by increasing the temperature to $40^{\circ} \mathrm{C}$ with some loss of selectivity (compare entry 3 and 4). Diene 1 and $\mathrm{NH}$-maleimide (3) were also combined at $5^{\circ} \mathrm{C}$ (entry 2 ). Diastereomer $R$ is now the major compound, showing that the approach direction of reagents is highly dependent of temperature. A possible interpretation for this fact may be an establishment of a hydrogen bond in the approach of maleimide by the re face of the diene as shown in figure 2. At higher temperature the hydrogen bond is probably not forming. There is an enormous amount of information in the lit. trying to connect the outcome of DA cycloadditions with a possible hydrogen bond effect between reagents. ${ }^{3 a-g}$ The idea of the effect of a hydrogen bond is reinforced by the result of the experiment carried out at $5^{\circ} \mathrm{C}$ by combining diene 2 and $N$ phenylmaleimide (4), which has no possibility of forming a hydrogen bond. The major isomer is the $S$ configuration as happen at rt (compare entries 5 and 6), with selectivity improvement. The result obtained shows a different trend from the one that came out by comparing entries 2 and 3.

Table 1. Diels-Alder cycloadditions of dienes 1 e $\mathbf{2}$ with $N H$-maleimide $\mathbf{3}$ and $N$-phenylmaleimide 4

\begin{tabular}{|c|c|c|c|c|c|c|c|c|}
\hline & Entry & Diene & $\begin{array}{l}\text { Dienophile } \\
\text { (2eq.) }\end{array}$ & Product & $\begin{array}{c}\text { Solvent } \\
\mathrm{T} /{ }^{\circ} \mathrm{C}\end{array}$ & time & $\begin{array}{l}d . r . \\
(S / R)\end{array}$ & $\begin{array}{c}\eta(\%) \\
5 S / 6 R\end{array}$ \\
\hline & 1 & 1 & 4 & $5 a / 6 a$ & $\begin{array}{c}\text { toluene } \\
\mathrm{rt}\end{array}$ & $3 d$ & $1^{a)}: 1$ & $22-23$ \\
\hline & 2 & 1 & 3 & $5 b / 6 b$ & $\begin{array}{c}\mathrm{CH}_{2} \mathrm{Cl}_{2} \\
5\end{array}$ & $18 \mathrm{~d}$ & $1: 2$ & $30-19$ \\
\hline & 3 & 1 & 3 & $5 b / 6 b$ & $\begin{array}{c}\mathrm{CH}_{2} \mathrm{Cl}_{2} \\
\mathrm{rt}\end{array}$ & $5 d$ & $3: 1$ & b) \\
\hline & 4 & 1 & 3 & $5 b / 6 b$ & $\begin{array}{c}\mathrm{CH}_{2} \mathrm{Cl}_{2} \\
40\end{array}$ & $15 \mathrm{~h}$ & $2: 1$ & $33-21$ \\
\hline & 5 & 2 & 4 & $5 c / 6 c$ & $\begin{array}{c}\mathrm{CH}_{2} \mathrm{Cl}_{2} \\
\mathrm{rt}\end{array}$ & $9 d$ & $2: 1$ & $43-20$ \\
\hline & 6 & 2 & 4 & $5 c / 6 c$ & $\begin{array}{c}\mathrm{CH}_{2} \mathrm{Cl}_{2} \\
5\end{array}$ & $18 \mathrm{~d}$ & $3: 1$ & $22-4^{c)}$ \\
\hline & 7 & 2 & 3 & $5 d / 6 d$ & $\begin{array}{c}\mathrm{CH}_{2} \mathrm{Cl}_{2} \\
\mathrm{rt}\end{array}$ & $5 \mathrm{~d}$ & $3: 1$ & $41-39^{d)}$ \\
\hline \multicolumn{9}{|c|}{$\begin{array}{l}\text { submitted to X-Ray analysis } \\
\text { not isolated; } d . r \text {. obtained by }{ }^{1} \mathrm{H} \text { RMN spectroscopy } \\
\text { an extra } 11 \% \text { amount of a } 1: 1 \text { mixture of } R \text { and } S \text { iso }\end{array}$} \\
\hline
\end{tabular}


d) $39 \%$ is not pure $R$ isomer; it is formed by a $1(S): 2.9(R)$ mixture of isomers based on ${ }^{1} \mathrm{H}$ RMN spectra of the sample

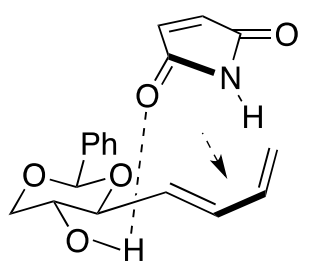

attack on the re face

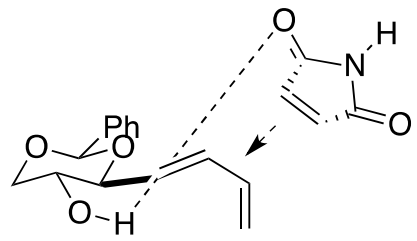

attack on the si face

Figure 2 -Approach of maleimide (3) to diene $\mathbf{1}$ in the re / si face showing the formation of a hydrogen bond between reagents

$R / S$ Configurations of the products were found by comparison of ${ }^{1} \mathrm{H}$ NMR spectra of both isomers in each case to compounds $5 \mathbf{a} / \mathbf{6 a}$. The identity of $5 \mathbf{a}$ was unequivocally confirmed by X-ray crystallography. (Figure 3) The chemical shifts of H-5 / H-2' differ between isomers and the difference is reproducible in every case. ${ }^{4}$ Product $\mathbf{6 a}$ is an endo product as $\mathbf{5 a}$, according to n.o.e. experiment. Irradiation of $\mathrm{H}-5^{\prime}$ and $\mathrm{H}-7 \mathrm{a}$ leads to an increase of $\mathrm{H}-4$ signals in $6.27 \%$ and $10.4 \%$ respectively.

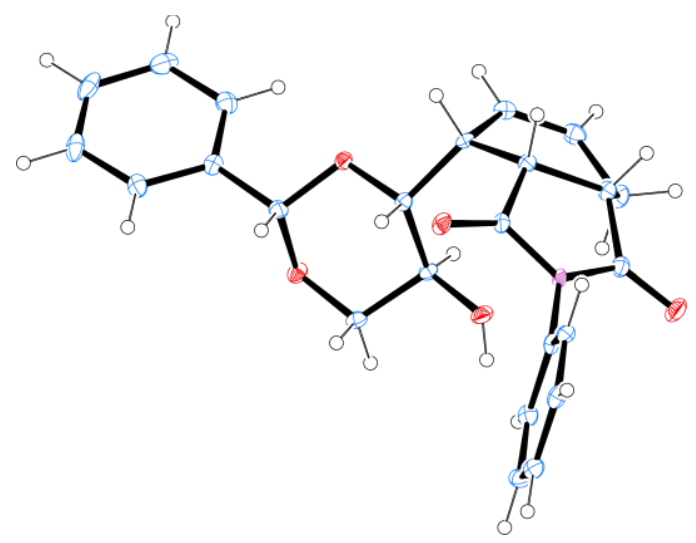

Figure 3- ORTEP view of diasteromer 5a

To improve the facial selectivity of these DA cycloadditions it was decided to self-assembly the reagents by tethering erythrose diene 1 and maleimides 3 /4 in a LACASA-DA cycloaddition using bimetallic complex of $\mathrm{Mg}$ (II) and $\mathrm{Zn}(\mathrm{II})$ coordination in which $R$ - and $S$-BINOL were chiral inductors. This implies an important advantage over the simple Lewis acid catalysis because covalent bonds to the metals are established and the reaction is almost an intramolecular cycloaddition as shown in scheme 2. This method has been first developed by 
Inomata $^{5 \mathrm{a}, \mathrm{b}}$ using a tartaric acid-zinc complex in reaction of nitroso dienophiles with a dienol, and later by Ward. ${ }^{6 a, b}$

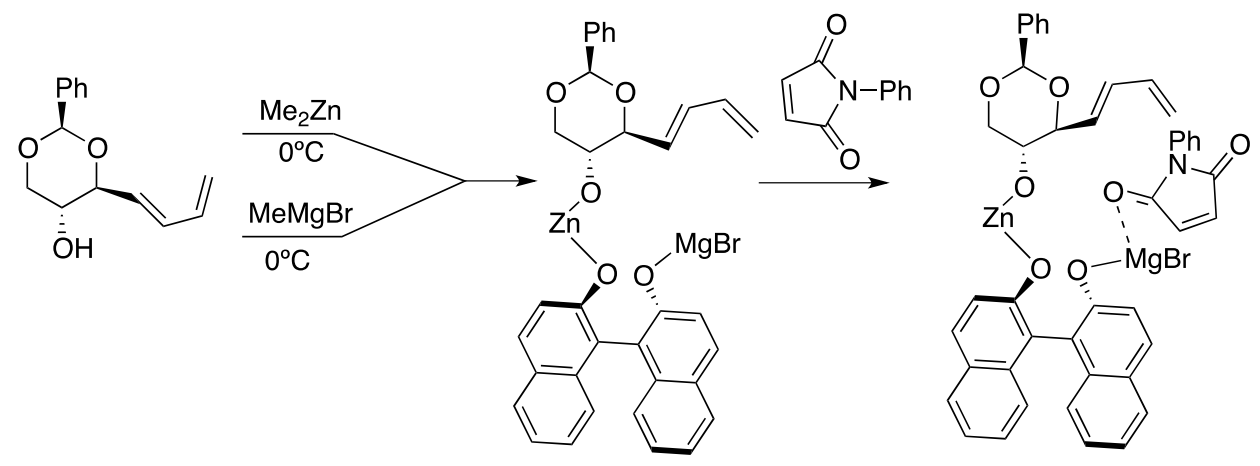

Scheme 2- Bimetalic complex of $\mathrm{Mg}(\mathrm{II})$ and $\mathrm{Zn}$ (II) assembling together diene 1, $\mathrm{N}$-phenylmaleimide (4) and $R$-BINOL

The reaction that combines $S$-BINOL (A), $N H$-maleimide, and diene $\mathbf{1}$ is completely selective, forming exclusively the $S$ product in $33 \%$ yield. ${ }^{7}$ Figure 4 represents the assembly of the reagents and the direction of attack of maleimide to the front face of the diene leading to the $S$ product. The high selectivity observed is probably due to the covalent bond between the $\mathrm{Mg}$ and the nitrogen atom that forces the anterofacial interaction. The assembly of $R$-BINOL $(\mathbf{B}), N H$ maleimide and diene 1 give also a single $S$ configuration product (35\%). This means that although the flexibility of the complex is higher in case $\mathbf{B}$, a similar approach is taking place.
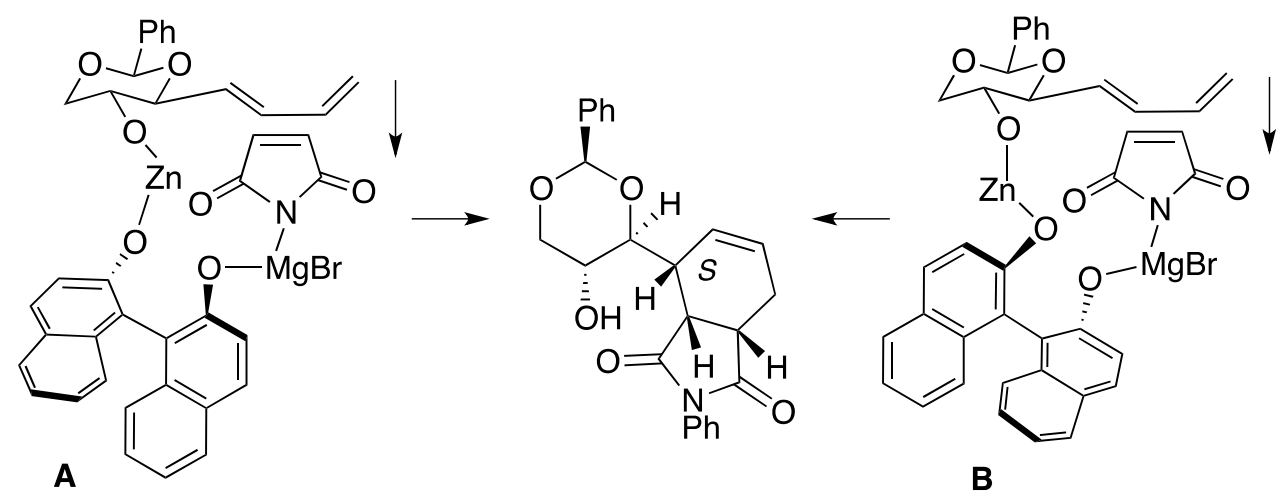

Figure 4 - Coordination of the erythrose diene 1 with $\mathrm{NH}$-maleimide (1) using bimetalic complex of $\mathrm{Mg}(\mathrm{II})$ and $\mathrm{Zn}(\mathrm{II})$ with $S$-BINOL (A) and $R$-BINOL (B).

When $N$-phenylmaleimide replaced $N H$-maleimide, in the complex with $R$-BINOL and diene 1 a 2.5:1 ratio of isomers was obtained, in $50 \%$ global yield, favoring the $R$ compound. Both 
isomers were isolated in $35 \%(R)$ and $15 \%(S)$ yields. In this case no covalent bond could have been established and the reaction attack of the dienophile could now occur by the less bulky rear face of the diene.

In conclusion $\mathrm{NH}$ - and $\mathrm{NPh}$-maleimides were combined to erythrose dienes $\mathbf{1}$ and $\mathbf{2}$ showing at its best a 1:3 ratio of isomers. It was even possible to revert the selectivity playing with the reaction temperature. Products can be effectively separated in the majority of the cases by column chromatography. Single $S$ isomers were isolated in moderate yields in the case of $\mathrm{NH}$ maleimide (3) and diene 1 by using bimetallic complex templates of $\mathrm{Zn}$ (II) and $\mathrm{Mg}$ (II) and $R$ or $S$-BINOL. Combination of diene 1, $N$-phenylmaleimide (4) and $R$-BINOL in the same conditions led to the $R$ isomer (35\% yield) together $S$ isomer (15\% yield).

Acknoledgments Thanks are due to FCT for project funding PTDC/QUI/67407/2006 and FCT and FEDER for funding NMR spectrometer Bruker Avance III 400 as part of the National NMR Network.

\section{References}

1- Mukhopadhyay, A.; Ali, S.M.; Husain, M.; Suryawanshi, S.N.; Bhakuni, D.S. Tetrahedron Lett. 1989, 30, 1853-1856.

2- Alves, M.J.; Duarte, V.C.M.; Faustino, H.; Gil Fortes, A. Tetrahedron: Asymmetry 2010, 21, $1817-1820$.

3- a) Jones, D.W. J. Chem. Soc., Chem. Commun. 1980, 739-740. b) Fisher, M.J.; Hehre, W.J.; Kahn, S.D.; Overman, L.E. J. Am. Chem. Soc. 1988, 110, 4625-4633. c) Trost, B.M.; Lee, D.C. J. Org. Chem. 1989, 54, 2271-2274. d) Macaulay, J.B.; Fallis, A.G. J. Am. Chem. Soc., 1988, 110, 4074-4076. e) Macaulay, J.B.; Fallis, A.G. J. Am. Chem. Soc., 1990, 112, 1136-1144. f) Tripathy, R.; Carrol, P.J.; Thornton, E.R. J. Am. Chem. Soc. 1990, 112, 6743-6744. g) Tripathy, R.; Carrol, P.J.; Thornton, E.R. J. Am. Chem. Soc. 1991, 113, 7630-7640.

4- Compound 5a: H-5: 6.40 (dt, J 3.2, 9.2 Hz), H-2': 5.64 (s); compound 5b: H-5: 6.38 (dt, $J$ 3.6, $9.2 \mathrm{~Hz}$ ), H-2': 5.66 (s); compound 5c: H-5: 6.34 (dt, J 3.6, $9.2 \mathrm{~Hz}$ ); H-2': 5.67 (s); compound 5d: H-5: 6.28 (dt, J 3.6, 9.2 Hz), H-2': 5.67 (s); compound 6a: H-5: 6.17 (dt, J 3.2, $9.2 \mathrm{~Hz}$ ), H-2': 5.51 (s); compound 6b: H-5 - 6.12 (dt, J 3.6, 9.6 Hz), H-2': 5.54 (s); compound 6c: H-5: 6.16 (br s) ${ }^{\text {a) }}$, H-2': 5.42 (s); compound 6d: H-5: 6.08 (br t, 2.0 Hz) ${ }^{\text {a) }}$, H-2': 5.42 (s).

a) these signals coincide with H-6. 
5- a) Ding, X.; Ukaji, Y.; Fujinami, S.; Inomata, K. Chem. Lett., 2003, 32, 582-583. b) Ukaji, Y.; Inomata, K. Synlett, 2003, 1075-1087.

6- a) Ward, D.E.; Souweha; M.S. Org. Lett. 2005, 3533-3536. b) Ward, D.E.; Mohammad; S.A. Org. Lett. 2000, 3937-3940.

7- Preparation of solution A - A solution of diene 1 (0.05 g; $0.22 \mathrm{mmol})$ in dry toluene (1.0 $\mathrm{mL})$ was added to a solution of $\mathrm{Me}_{2} \mathrm{Zn} 1.2 \mathrm{M}$ in toluene $(178 \mu \mathrm{L} ; 0.22 \mathrm{mmol})$ at $0{ }^{\circ} \mathrm{C}$ and stirred for $5 \mathrm{~min}$. Preparation of solution B - A solution of $(S)$-BINOL (0.061 g; $0.22 \mathrm{mmol})$ in dry toluene $(1.0 \mathrm{~mL})$ was added to a solution of $\mathrm{MeMgBr}(1.4 \mathrm{M}$ in toluene/THF; $152 \mu \mathrm{L} ; 0.22$ mmol) at $0{ }^{\circ} \mathrm{C}$ and stirred for 5 min. Solution $\mathbf{A}$ was added to solution $\mathbf{B}$, diluted with dry toluene $(1.8 \mathrm{~mL})$ and stirred for $5 \mathrm{~min}$. This mixture was refrigerated at $-78{ }^{\circ} \mathrm{C}$ and a solution of $\mathrm{NH}$-maleimide $(0.02 \mathrm{~g} ; 0.22 \mathrm{mmol})$ in dry toluene $(1.5 \mathrm{~mL})$ was then added. The temperature was left to rise gradually till $\mathrm{rt}$. The reaction was complete after $17 \mathrm{~d}$ and was quenched with aq. sat. sol. $\mathrm{NaHCO}_{3}(1 \mathrm{~mL})$, passed through a pad of celite ${ }^{\circledR}$ and washed with ethyl acetate $(4 \times 10$ $\mathrm{mL})$. The filtrates were combined and concentrated in vacuum to give a yellow oil that was submitted to "dry-flash" chromatography using a mixture of petroleum ether $40-60{ }^{\circ} \mathrm{C} / \mathrm{ether}$, crescent polarity. $(S)$-BINOL was recovered $(0.035 \mathrm{~g} ; 57 \%)$ from petroleum ether / ether 1:1, and the product was eluted with petroleum ether / ether 1:2.3 (0.024 g; $33 \%)$. 